\title{
Mechanical Thrombectomy for Transcatheter Aortic Valve Insertion (TAVI)-Related Periprocedural Stroke: Current Literature and Future Directions
}

\author{
Authors: \\ *Suleiman Suleiman, Richard Szirt, J.J. Coughlan \\ 1. Department of Cardiology, St. James's Hospital, Dublin, Ireland \\ *Correspondence to suleimas@tcd.ie \\ Disclosure: $\quad$ The authors have declared no conflicts of interest. \\ Received: \\ 03.03 .20 \\ Accepted: \\ 14.04 .20 \\ Keywords: \\ Acute ischaemic stroke, aortic valve implantation, embolic debris, endovascular \\ revascularisation, periprocedural, stroke, thrombolysis, transcatheter aortic valve \\ implantation (TAVI), transcatheter aortic valve replacement (TAVR), transcatheter \\ mechanical thrombectomy.
}

Citation:

EMJ Int Cardiol. 2020;DOI/10.33590/emjintcardiol/20-00054

\section{Abstract}

Transcatheter aortic valve implantation (TAVI) has dramatically altered the treatment of highrisk patients with symptomatic, severe aortic stenosis. Its utilisation has also begun to extend into intermediate- and low-surgical risk patients. Despite major advancements in the field of TAVI, stroke remains a significant complication because of its high mortality and morbidity rate. This article reviews the role of mechanical thrombectomy (MT) in the management of TAVI-related periprocedural stroke. A comprehensive literature search was performed for studies to include in this systematic review of MT in periprocedural and post-TAVI stroke patients. The search identified 11 case reports in which MT was utilised to treat periprocedural stroke successfully. MT without thrombolysis has several potential benefits for TAVI-related periprocedural stroke because a large proportion of strokes are secondary to nonthrombotic emboli and there is a high bleeding risk associated with patients undergoing TAVI. The authors propose that centres undertaking TAVI procedures have dedicated thrombolysis and thrombectomy pathways for patients who experience a TAVI-related periprocedural stroke.

\section{INTRODUCTION}

Transcatheter aortic valve insertion (TAVI) has dramatically altered the treatment of patients with symptomatic, severe aortic stenosis and is currently the treatment of choice for patients deemed high risk for surgical aortic valve replacement (SAVR). ${ }^{1}$ With the results of recent trials, the use of TAVI has also begun to extend into intermediate- and low-surgical risk patients. ${ }^{2-4}$ These encouraging results in low-risk patients will likely further increase the utilisation of TAVI in modern practice.

Stroke remains an important complication of TAVI and is associated with significant morbidity and mortality. ${ }^{5}$ Thirty-day stroke rates in highand intermediate-risk patients undergoing TAVI have been reported to range from 1.4-1.9\%. ${ }^{6-9}$ For TAVI-related periprocedural stroke, mechanical thrombectomy (MT) with retrievable stents may provide several advantages over thrombolysis alone. Concerns related to TAVI- 
related periprocedural stroke management include: increased bleeding risk associated with thrombolysis in the elderly; contraindication to thrombolysis in heparinised patients; and concerns regarding the effectiveness of thrombolysis in the setting of stroke secondary to embolised nonthrombotic material. ${ }^{10}$ This article reviews the role of mechanical thrombectomy in the management of TAVI-related periprocedural stroke.

\section{BACKGROUND}

\section{Stroke Rate Post-Transcatheter Aortic Valve Implantation}

Contemporary data in high- and intermediaterisk patients undergoing TAVI show a 30-day stroke rate ranging from 1.4-1.9\%. ${ }^{6-9}$ Most recently, the PARTNER 3 trial has shown superiority of TAVI for the composite endpoint of mortality, stroke, and hospital readmission at 1 year (hazard ratio [HR] 0.38; 95\% confidence interval [Cl] 0.15-1.00) in comparison to SAVR. The Evolut Low Risk trial consisted of a longer follow-up of 2 years and reported non-inferiority of TAVI compared to SAVR regarding the composite primary end point of death and stroke (5.3\% versus $6.7 \%)$. However, stroke remains a significant complication of TAVI, and confers an increased risk of 30-day mortality (odds ratio [OR]: 6.45; 95\% confidence interval $[\mathrm{Cl}]$ : 3.9-10.6). ${ }^{3-5}$

\section{Timing of Transcatheter Aortic Valve Insertion (TAVI)-Related Periprocedural Stroke}

The temporal presentation of TAVI-related cerebrovascular events has been classified as bimodal with an early phase $(\leq 24 \mathrm{~h})$ and a late phase ( $>10$ days). Up to $50 \%$ of events occur within the first 24 hours after TAVI. ${ }^{11,12}$ Studies involving routine diffusion-weighted MRI (DW-MRI) postTAVI demonstrate that $60-90 \%$ of post-TAVI patients have new silent cerebral emboli. This appears to be independent of the mode of access or valve type utilised. ${ }^{13-15}$ The effect of these silent lesions on cognitive function after TAVI has been debated. ${ }^{16}$

\section{Aetiology of Transcatheter Aortic Valve Insertion-Related Periprocedural Stroke}

Most acute cerebrovascular events post-TAVI are classified as ischaemic, with $<5 \%$ attributed to haemorrhage." The aetiology and predictors of these strokes mainly relate to procedural factors. The aetiology of acute periprocedural strokes includes atheromatous and calcific emboli caused by wire, catheter, and valve manipulation, balloon aortic valvuloplasty, and valve deployment.10,17 Other causes of acute stroke include air embolism and global cerebral hypoperfusion. ${ }^{17}$

The PARTNER trial established that minimal aortic valve area was a predictor of cerebrovascular insult in the initial course post-TAVI." This was related to a higher degree of valve calcification, which in turn increased the likelihood of balloon post-dilation. ${ }^{18}$ Other predictors of early phase cerebrovascular events included number of implantation attempts, valve embolisation, and need for second valve implantation.12,19,20 Total time in the catheterisation laboratory, total time of delivery system in the body, and rapid pacing during valvuloplasty were also associated with increased rates of acute stroke..$^{21}$ Less experience in implantation was also associated with higher stroke rates, though this was very minimal (2.03\% versus $1.66 \%, p=0.01)^{22}$

\section{Strategies to Reduce Transcatheter Aortic Valve Insertion-Related Periprocedural Stroke}

To attempt to reduce thrombotic events, the majority of centres utilise intravenous heparin to obtain anticoagulation throughout the procedure, although $27.6 \%$ of centres do not monitor activated clotting time to guide anticoagulation. ${ }^{23,24}$ Cerebral embolic protection devices (CEPD) have been associated with a reduction in the volume of silent ischaemic emboli, however a recent meta-analysis was unsuccessful in establishing a decline in the number of single or multiple ischaemic lesions. ${ }^{25,26}$ Though a significant reduction in 30-day stroke rate has been shown, CEPD had no effect on 30day mortality. ${ }^{25}$ 


\section{Histological Analysis of Emboli in Transcatheter Aortic Valve Insertion- Related Periprocedural Stroke}

A study by Van Mieghem et al. ${ }^{27}$ utilised a dual filter-based CEPD in 40 patients undergoing TAVI. Embolic debris bound for the cerebrum was caught in $75 \%$ of TAVI procedures. Tissue fragments compatible with aortic valve leaflet or aortic wall tissue were found in 52\% (21 of 40) of patients; $20 \%$ consisted of thrombus alone and $25 \%$ had no debris identified. ${ }^{27}$ This non-clot embolic debris can lead to immediate cerebral ischaemia or may subsequently provoke delayed thrombus development. This may explain why the clinical symptoms and diagnosis of early postTAVI stroke can be delayed for up to 10 days. ${ }^{10}$ This is crucial as this non-clot debris would not be amenable to thrombolysis. General anaesthesia and sedation can also delay diagnosis of periprocedural strokes. ${ }^{10}$

\section{Management of Transcatheter Aortic Valve Insertion-Related Periprocedural Stroke}

When stroke is suspected, rapid access to CT of the brain, CT cerebral angiography, and specialist review, ideally by a stroke team, have been recommended. ${ }^{10}$ A Cochrane review comparing $\mathrm{CT}$ and MRI against the clinical diagnosis highlighted that DW-MRI was substantially more sensitive than CT imaging. ${ }^{28} \mathrm{DW}-\mathrm{MRI}$ also has the advantage of precisely quantifying brain ischaemia. The authors did not specifically comment on thrombolysis, however, they suggest that MT may have a potential role in acute and late-presenting stroke following TAVI, based on anecdotal evidence in the literature. ${ }^{29}$

\section{LITERATURE REVIEW}

A comprehensive literature search was performed for studies to include in this systematic review of MT in patients with periprocedural or post-TAVI stroke. Databases including Medline, Pubmed, Embase, and the Cochrane Library were searched using the following terms: "stroke", "mechanical thrombectomy", "thrombectomy", "transcatheter aortic valve insertion", "transcatheter aortic valve replacement", "tavi”, "tavr”, "neurovascular rescue", and "stent retriever" in various combinations with Boolean operators "OR" and
"AND". The literature search was not limited by year. One author performed the initial search to identify potential studies for inclusion (SS). These were subsequently reviewed by co-authors (JJC, RS) and a final decision regarding studies to be included in the final analysis was made.

Inclusion criteria for identified studies were: studies published in English, studies reporting patients receiving TAVI for aortic valve disease, studies reporting patients affected by TAVIrelated periprocedural stroke, and studies reporting thrombectomy utilised with or without thrombolysis for the management of TAVI-related periprocedural stroke. Exclusion criteria included: studies not published in English, studies reporting noncerebral emboli, and studies reporting thrombolysis utilised without thrombectomy.

\section{RESULTS}

The search identified 11 case reports involving 11 patients (five male, six female), summarised in Table 1. Ages ranged from 73-98 years. Transfemoral approach was utilised in the majority of cases (90.9\%). The prosthetic valve types implanted included six balloon-expandable valves (three Edwards SAPIEN 3, three Edwards SAPIEN XT) and two self-expanding valves (two Medtronic CoreValves ${ }^{\mathrm{TM}}$ ). In three case reports the valve type utilised was not disclosed. The timing of the stroke was acute in most cases: six patients had 'on the table' strokes during their procedure, four patients were diagnosed with stroke immediately post-extubation or reversal of anaesthesia, and one was a late stroke, occurring 10 days post-TAVI. The left middle cerebral artery (MCA) was most commonly involved, with eight of the patients experiencing either a partial or complete occlusion of the left MCA; the remaining three patients had right MCA occlusions. Of the 11 patients, nine underwent thrombectomy alone (81.8\%) and two patients underwent combined thrombectomy and thrombolysis (18.2\%). Histology of retrieved embolised material demonstrated either aortic wall or valvular tissue in $63.6 \%$ of patients ( 7 of 11 ). All patients demonstrated a significant reduction in National Institutes of Health Stroke Scale (NIHSS) score post-thrombectomy. 
Table 1: Review of all published cases of mechanical thrombectomy for TAVI-related periprocedural stroke.

\begin{tabular}{|c|c|c|c|c|c|c|c|c|c|c|}
\hline Author & $\begin{array}{l}\text { TAVI } \\
\text { access }\end{array}$ & Valve type & Age & Sex & $\begin{array}{l}\text { Timing of } \\
\text { stroke }\end{array}$ & $\begin{array}{l}\text { Location } \\
\text { of lesion }\end{array}$ & $\begin{array}{l}\text { Thrombectomy/ } \\
\text { thrombolysis }\end{array}$ & $\begin{array}{l}\text { NIHSS or } \\
\text { symptoms pre/ } \\
\text { post }\end{array}$ & $\begin{array}{l}\text { Embolic } \\
\text { material } \\
\text { histology }\end{array}$ & $\begin{array}{l}\text { Bleeding } \\
\text { complication }\end{array}$ \\
\hline $\begin{array}{l}\text { Coughlan et } \\
\text { al.,29 } 2017\end{array}$ & TF & $\begin{array}{l}\text { Edwards } \\
\text { Sapien } 3\end{array}$ & 80 & M & On table & $\begin{array}{l}\text { Left MCA } \\
\text { (M2) }\end{array}$ & Thrombectomy & $19 / 5$ & $\begin{array}{l}\text { Thrombus, } \\
\text { calcified } \\
\text { aortic valve } \\
\text { fragment }\end{array}$ & Nil \\
\hline $\begin{array}{l}\text { D'Anna et } \\
\text { al., }{ }^{30} 2019\end{array}$ & TF & ND & 98 & M & On table & Left MCA & Thrombectomy & $24 / 3$ & Thrombus & Nil \\
\hline $\begin{array}{l}\text { Matsuo et } \\
\text { al., }{ }^{31} 2017\end{array}$ & TF & $\begin{array}{l}\text { Edwards } \\
\text { Sapien XT }\end{array}$ & 90 & $\mathrm{~F}$ & $\begin{array}{l}\text { Day } 10 \\
\text { post-TAVI }\end{array}$ & Left MCA & Thrombectomy & 19/11 & Thrombus & Nil \\
\hline $\begin{array}{l}\text { Wollenweber } \\
\text { et al.,32 } 2016\end{array}$ & TF & $\begin{array}{l}\text { Edwards } \\
\text { Sapien } 3\end{array}$ & 80 & $\mathrm{~F}$ & On table & Left MCA & Thrombectomy & $\begin{array}{l}\text { Global aphasia } \\
\text { and severe } \\
\text { right-sided } \\
\text { hemiparesis/ } \\
\text { mild expressive } \\
\text { aphasia and a } \\
\text { latent palsy of } \\
\text { the right leg }\end{array}$ & $\begin{array}{l}\text { Endothelial } \\
\text { arterial vessel } \\
\text { wall tissue }\end{array}$ & Nil \\
\hline $\begin{array}{l}\text { Alqahtani et } \\
\text { al.,332018 }\end{array}$ & ND & ND & 80 & $F$ & On table & $\begin{array}{l}\text { Left MCA } \\
\text { (M1) }\end{array}$ & Thrombectomy & $31 / 5$ & $\begin{array}{l}\text { Fibrous } \\
\text { stroma with } \\
\text { a myxoid } \\
\text { appearance }\end{array}$ & Nil \\
\hline $\begin{array}{l}\text { Gülker et } \\
\text { al.,34 } 2015\end{array}$ & TF & $\begin{array}{l}\text { Edwards } \\
\text { Sapien XT }\end{array}$ & 78 & F & On table & Left MCA & $\begin{array}{l}\text { Thrombolysis, } \\
\text { followed by } \\
\text { thrombectomy }\end{array}$ & $27 / 0^{*}$ & $\begin{array}{l}\text { Tissue } \\
\text { fragment of } \\
\text { degenerated } \\
\text { Hancockä II } \\
\text { bioprosthesis }\end{array}$ & Nil \\
\hline $\begin{array}{l}\text { Hamandi et } \\
\text { al.,35 } 2018\end{array}$ & TF & $\begin{array}{l}\text { Edwards } \\
\text { Sapien } 3\end{array}$ & 73 & M & $\begin{array}{l}\text { After } \\
\text { extubation }\end{array}$ & Left MCA & $\begin{array}{l}\text { Thrombolysis, } \\
\text { followed by } \\
\text { thrombectomy }\end{array}$ & $\begin{array}{l}\text { Decreased } \\
\text { responsiveness, } \\
\text { dysarthria, and } \\
\text { right-sided } \\
\text { hemiparesis/O }\end{array}$ & ND & Nil \\
\hline $\begin{array}{l}\text { Miura et al.,36 } \\
2017\end{array}$ & TF & $\begin{array}{l}\text { Edwards } \\
\text { Sapien XT }\end{array}$ & 82 & M & $\begin{array}{l}\text { After } \\
\text { extubation }\end{array}$ & $\begin{array}{l}\text { Right } \\
\text { MCA (M1) }\end{array}$ & Thrombectomy & $\begin{array}{l}\text { Disturbance of } \\
\text { consciousness } \\
\text { and paralysis of } \\
\text { the left side of } \\
\text { the body/0 }\end{array}$ & $\begin{array}{l}\text { Intimal fibrous } \\
\text { plaque } \\
\text { derived from } \\
\text { aortic wall }\end{array}$ & Nil \\
\hline $\begin{array}{l}\text { Fassa et al.,37 } \\
2014\end{array}$ & TF & CoreValveä & 90 & F & On table & $\begin{array}{l}\text { Right } \\
\text { MCA (M1- } \\
\text { M2) }\end{array}$ & Thrombectomy & $\begin{array}{l}\text { Unresponsive/ } \\
\text { fully responsive } \\
\text { and orientated } \\
\text { with modified } \\
\text { Rankin Scale } \\
\text { score O }\end{array}$ & $\begin{array}{l}\text { Pure calcific } \\
\text { fragment: } \\
\text { likely native } \\
\text { aortic valve or } \\
\text { aortic wall }\end{array}$ & Nil \\
\hline $\begin{array}{l}\text { Anuwatworn } \\
\text { et al.,38 } 2015\end{array}$ & TF & CoreValve & 78 & M & $\begin{array}{l}\text { On } \\
\text { awakening } \\
\text { from } \\
\text { sedation }\end{array}$ & $\begin{array}{l}\text { Left MCA } \\
\text { (M1) }\end{array}$ & Thrombectomy & $\begin{array}{l}\text { Right } \\
\text { hemiplegia/ } \\
\text { heart valve } \\
\text { tissue }\end{array}$ & & Nil \\
\hline $\begin{array}{l}\text { Salinas et } \\
\text { al. }{ }^{39} 2013\end{array}$ & TF & ND & 88 & F & $\begin{array}{l}\text { After } \\
\text { prompt } \\
\text { reversal of } \\
\text { anesthesia }\end{array}$ & $\begin{array}{l}\text { Right } \\
\text { MCA (M1) }\end{array}$ & Thrombectomy & $\begin{array}{l}\text { Complete left } \\
\text { hemiparesis/ } \\
\text { modified Rankin } \\
\text { scale } 1\end{array}$ & Thrombus & Nil \\
\hline
\end{tabular}

*authors reported patient had a full recovery of symptoms; assumption of a NIHSS score of O.

F: female; M: male; MCA: middle cerebral artery (M1 or M2 segments); ND: not disclosed; NIHSS: National Institutes of Health stroke scale; TAVI: transcatheter aortic valve insertion; TF: transfemoral.

\section{DISCUSSION}

day mortality. ${ }^{5-9}>50 \%$ of strokes occur in the first 24 hours post-TAVI. ${ }^{11,12}$ The management of acute ischaemic stroke (AIS) has been revolutionised

TAVI-related periprocedural stroke is a in recent years with the widespread adoption of catastrophic complication with a high risk of 30- MT. MT is now considered the gold standard of 
care for all AIS with large vessel occlusions. ${ }^{40}$ It has been well established that MT paired with intravenous thrombolysis (IVT) demonstrates favourable outcomes for functional independence, health-related quality of life, and cognitive function at long-term follow-up for patients with AIS, when compared to standard medical therapy alone. ${ }^{41-43}$ This article describes all published cases of MT post-TAVI. MT was utilised successfully in all 11 published cases, with a significant reduction in NIHSS score and no complications postrecanalisation. This suggests that MT represents a potentially efficacious and safe management strategy for TAVI-related periprocedural stroke.

Recent data from the DAWN and DIFFUSE-3 trials have highlighted that the time window for MT can be extended past the traditional 6 hours, to 24 hours. ${ }^{44,45}$ This is important since the recognition and diagnosis of TAVI-related strokes may be delayed past the 4.5 hour thrombolysis window, because of factors including general anaesthesia and procedural sedation. ${ }^{10}$

Combined treatment with IVT prior to MT was utilised in two patients. There is ongoing debate in the literature as to whether IVT before MT is superior to MT alone in AIS. ${ }^{46}$ The American Heart Association (AHA) post-hoc analysis of the ASTER trial demonstrated that AIS patients treated with combined IVT and MT had lower 90day mortality compared with those undergoing MT alone. ${ }^{47}$ There were no significant differences between the IVT with MT and MT-alone groups in 90-day favourable functional outcome, successful reperfusion rate, NIHSS score improvement at 24 hours, or haemorrhagic complication rate. However, many of the studies contained only direct MT patients who were ineligible for IVT or where IVT was contraindicated, establishing a bias in which the MT-alone arm represented a patient cohort with a potentially increased morbidity and associated poorer outcome.48,49 Kaesmacher et al. ${ }^{50}$ proposed that when analyses were limited to cohorts with a reduced risk of selection bias, the data implied that MT alone might deliver comparable safety and efficacy to combined therapy. ${ }^{51}$

It is also difficult to directly extrapolate the results of these studies to patients undergoing TAVI. TAVI patients differ from the patients in these trials in several regards: the AIS occurs in the setting of a procedure; the patients are usually therapeutically anticoagulated with heparin at the time of the AIS; and the patients are generally older than patients in the MT trials, with a higher pre-stroke modified Rankin Scale and more comorbidities. ${ }^{50}$

As determined in this review of MT postTAVI, $63.6 \%$ of patients had embolic debris histologically consistent with valvular and aortic wall tissue. These emboli would not be expected to respond to thrombolysis. This was consistent with the literature highlighting that $>50 \%$ of debris collected by CEPD was nonthrombotic. ${ }^{27}$ This differs from published data analysing thrombus composition in traditional AIS treated with $\mathrm{MT}^{52}$ The use of thrombolysis would potentially be of no benefit in these circumstances and may increase the rate of bleeding complications.

In the SURTAVI trial, the PARTNER 2 trial, and the US CoreValve studies, life-threatening and major haemorrhagic complications within 30 days of TAVI were identified in $10.2 \%$ of patients. ${ }^{53-56}$ A meta-analysis by Wang et al. ${ }^{57}$ indicated that post-TAVI bleeding was associated with a $323 \%$ increase in 30-day postoperative mortality, and that these patients were $410 \%$ more likely to die than patients without bleeding. ${ }^{58}$ Physicians must be extremely cautious when considering thrombolysis in TAVI patients. The use of IVT may be relatively or absolutely contraindicated because of concurrent anticoagulation, increased activated partial thromboplastin time or activated clotting time, and high HAS-BLED score or bleeding risk.

Transfemoral access is the most-adopted approach for TAVI as it has a $20 \%$ relative reduction in mortality compared with SAVR. ${ }^{57}$ It is also the preferred access in MT. ${ }^{59}$ This is advantageous for the treatment of periprocedural strokes as there is the benefit of established femoral access. There is an ongoing debate regarding the training of cardiologists in performing MT, which is currently most often performed by interventional radiologists. ${ }^{60}$ Cardiologists have skills transferable to MT and extensive experience with emergency, timeconstrained interventions for patients with STelevation myocardial infarction. In the future, appropriately trained cardiologists may be able to perform MT in the cardiac catheterisation laboratory for patients experiencing TAVI-related 
periprocedural stroke. ${ }^{61}$ However, this requires a significant skillset, thorough training, and the requirement for many cases to become proficient.

While analysis of the published literature on MT post-TAVI provides interesting information, the high risk of publication bias must be acknowledged. As a result, mechanical thrombectomy alone may be a viable option to manage on-table stroke post-TAVI on a case by case basis, with or without thrombolysis. The SWIFT Direct trial is an ongoing prospective randomised controlled trial attempting to ascertain whether patients with an AIS secondary to large intracranial vessel occlusion in the anterior circulation will have non-inferior functional outcome at 90 days when managed with direct MT, compared to patients treated with bridging IVT prior to MT. ${ }^{62}$ This will hopefully shed further light on the optimal treatment strategies for AIS.

In the interim, the authors propose that centres undertaking TAVI procedures have dedicated thrombolysis and thrombectomy pathways for patients who experience a TAVI-related periprocedural stroke. This may be as elementary as stabilising the patient, rapid access to imaging, review by a stroke team, and possible commencement of thrombolysis, with subsequent transfer to a centre with the facilities to treat AIS with MT. Hopefully, by maximising the number of patients receiving these therapies, there can be a reduction in the associated stroke-related morbidity and mortality and an improvement in outcomes for patients.

\section{Limitations of the Manuscript}

As mentioned previously, there is a high risk of publication bias in reporting of MT post-TAVIrelated stroke. It is possible that only successful cases would be submitted for publication, and this review was unable to identify any published manuscripts detailing cases where MT was unsuccessful in the treatment of AIS. Secondly, all cases identified were case reports and there are no prospective randomised controlled trials investigating the treatment of TAVI-related periprocedural stroke.

\section{CONCLUSION}

MT has been described as a potential treatment for TAVI-related periprocedural stroke. MT without thrombolysis may have several potential benefits for TAVI-related periprocedural stroke because a large proportion of these strokes are secondary to non-thrombotic emboli and there is a high bleeding risk associated with patients undergoing TAVI. However, further research is required on the optimum management of TAVI-related strokes. TAVI centres should have dedicated MT pathways for TAVI-related periprocedural stroke. The SWIFT Direct trial will further provide further data regarding the benefit of IVT prior to MT.63

\section{References}

1. Makkar RR et al. Transcatheter aorticvalve replacement for inoperable severe aortic stenosis. N Engl J Med. 2012;366:1696-704.

2. Leon MB et al. Transcatheter or surgical aortic-valve replacement in intermediate-risk patients. N Engl J Med. 2016;374(17):1609-20.

3. Mack MJ et al. Transcatheter aorticvalve replacement with a balloonexpandable valve in low-risk patients. N Engl J Med. 2019;380(18):1695-705.

4. Popma JJ et al. Transcatheter aortic-valve replacement with a selfexpanding valve in low-risk patients. N Engl J Med. 2019;380(18):1706-15.

5. Muralidharan A et al. Meta-analysis of perioperative stroke and mortality in transcatheter aortic valve implantation. Am J Cardiol. 2016;118(7):1031-45.
6. Grube E et al. Clinical outcomes with a repositionable self-expanding transcatheter aortic valve prosthesis: the international FORWARD study. J Am Col Cardiol. 2017;70(7):845-53.

7. Wendler $O$ et al. SOURCE 3 registry: design and 30-day results of the European postapproval registry of the latest generation of the SAPIEN 3 transcatheter heart valve. Circulation. 2017;135(12):1123-32.

8. Forrest JK et al. Early outcomes with the Evolut PRO repositionable self-expanding transcatheter aortic valve with pericardial wrap. JACC Cardiovasc Interv. 2018;11(2):160-8.

9. Moellmann $\mathrm{H}$ et al. Real-world experience using the ACURATE neo prosthesis: 30-day outcomes of 1,000 patients enrolled in the SAVI TF registry. Eurolntervention. 2018;13(15):e1764-70.
10. Scarsini R et al. Impact of complications during transfemoral transcatheter aortic valve replacement: how can they be avoided and managed? J Am Heart. 2019;8(18):e013801.

11. Miller DC et al. Transcatheter (TAVR) versus surgical (AVR) aortic valve replacement: occurrence, hazard, risk factors, and consequences of neurologic events in the PARTNER trial. J Thorac Cardiovasc Surg. 2012;143(4):832-43.

12. Nombela-Franco $L$ et al. Timing, predictive factors, and prognostic value of cerebrovascular events in a large cohort of patients undergoing transcatheter aortic valve implantation. Circulation. 2012;126(25):3041-53.

13. Kahlert $P$ et al. Silent and apparent cerebral ischemia after 
percutaneous transfemoral aortic valve implantation. Am J Cardiol. 2009;104(6):30D.

14. Arnold M et al. Embolic cerebral insults after transapical aortic valve implantation detected by magnetic resonance imaging. JACC CardiovasC Inter. 2010;3(11):1126-32.

15. Astarci P et al. Magnetic resonance imaging evaluation of cerebral embolization during percutaneous aortic valve implantation: comparison of transfemoral and trans-apical approaches using Edwards Sapiens valve. Eur J Cardiothorac Surg. 2011;40(2):475-9.

16. Altisent $O A$ et al. Neurological damage after transcatheter aortic valve implantation compared with surgical aortic valve replacement in intermediate risk patients. Clin Res Cardiol. 2016;105(6):508-17.

17. Armijo $\mathrm{G}$ et al. Cerebrovascular events after transcatheter aortic valve implantation. Front Cardio Med. 2018;5:104.

18. Nombela-Franco $L$ et al. Predictive factors, efficacy, and safety of balloon post-dilation after transcatheter aortic valve implantation with a balloon-expandable valve. JACC Cardiovasc Inter. 2012;5(5):499-512.

19. Stortecky S et al. Cerebrovascular accidents complicating transcatheter aortic valve implantation: frequency, timing and impact on outcomes. Eurolntervention. 2012;8(1):62-70.

20. Tchetche D et al. Cerebrovascular events post-transcatheter aortic valve replacement in large cohort of patients: a FRANCE-2 registry substudy. JACC Cardiovasc Inter. 2014;7(10):1138-45.

21. Kleiman NS et al. Neurological events following transcatheter aortic valve replacement and their predictors: a report from the CoreValve trials. Circ Cardiovasc Interv. 2016 Sep;9(9):e003551.

22. Carroll JD et al. Procedura experience for transcatheter aortic valve replacement and relation to outcomes: the STS/ACC TVT registry. J Am Col Cardiol. 2017;70(1):29-41.

23. Cerrato E et al. Evaluation of current practices in transcatheter aortic valve implantation: the WRITTEN (WoRldwlde TAVI ExperieNce) survey. Int J Cardiol. 2017;228:640-7.

24. Dangas GD et al. Bivalirudin versus heparin anticoagulation in transcatheter aortic valve replacement: the randomized BRAVO-3 trial. J Am Col Cardiol. 2015;66(25):2860-8

25. Testa $L$ et al. Cerebral protection during transcatheter aortic valve implantation: an updated systematic review and meta-analysis. J Am Heart. 2018;7(10):e008463.

26. Bagur R et al. Cerebral embolic protection devices during transcatheter aortic valve implantation: systematic review and meta-analysis. Stroke. 2017;48(5):1306-15.

27. Van Mieghem NM et al. Histopathology of embolic debris captured during transcatheter aortic valve replacement. Circulation. 2013;127(22):2194-201.

28. Brazzelli $M$ et al. Magnetic resonance imaging versus computed tomography for detection of acute vascular lesions in patients presenting with stroke symptoms. Cochrane Database Syst Rev. 2009(4)

29. Coughlan JJ et al. Mechanical thrombectomy of embolised native aortic valve post-TAVI. BMJ. 2017;2017.

30. D'Anna L et al. Intravenous thrombolysis and mechanical thrombectomy in patients with stroke after TAVI: a report of two cases. J Stroke Cerebrovasc Dis. 2019;28(10):104277.

31. Matsuo K et al. Successful cerebra thrombectomy for a nonagenarian with stroke in the subacute phase after transcatheter aortic valve implantation. Surg Neurol Internat. 2017;8.

32. Wollenweber FA et al. Thrombectomy recovers an aortic wall fragment from middle cerebral artery immediately after TAVI. Neurology. 2016;86(22):2111-2.

33. Alqahtani SA et al. Cerebral embolus from aortic valve fragment. JAMA. 2018;75(8):1022-3.

34. Gülker JE et al. Case report: cerebral stent retriever thrombectomy of an embolized valve fragment after valve in valve TAVI. Clin Res Cardiol. 2016;105(4):372-5.

35. Hamandi M et al. Acute stroke intervention after transcatheter aortic valve replacement. Baylor University Medical Center Proceedings. 2018;31(4):490-2.

36. Miura M et al. Successful stentretriever thrombectomy for acute cerebral embolization after transcatheter aortic valve implantation. Circulation. 2017:81(5):761-2.

37. Fassa AA et al. Successful endovascular stroke rescue with retrieval of an embolized calcium fragment after transcatheter aortic valve replacement. Circ Cardiovasc Interv. 2014;7(1):125-6.

38. Anuwatworn A et al. Stroke with valve tissue embolization during transcatheter aortic valve replacement treated with endovascular intervention. JACC Cardiovasc Inter. 2015;8(9):1261-3.

39. Salinas $P$ et al. Neurovascular rescue for thrombus-related embolic stroke during transcatheter aortic valve mplantation. JACC Cardiovasc Inter. 2013;6(9):981-2.

40. Bhogal $P$ et al. Mechanical thrombectomy-a brief review of a revolutionary new treatment for thromboembolic stroke. Clin Neuroradiol. 2018;28(3):313-26.

41. Jovin TG et al. Thrombectomy within 8 hours after symptom onset in ischemic stroke. $\mathrm{N}$ Eng J Med. 2015;372(24):2296-306

42. Berkhemer OA et al. A randomized trial of intraarterial treatment for acute ischemic stroke. $\mathrm{N}$ Engl J Med. 2015;372:11-20

43. Broderick JP et al. Endovascular therapy after intravenous t-PA versus t-PA alone for stroke. N Engl J Med. 2013;368(10):893-903.

44. Nogueira RG et al. Thrombectomy 6 to 24 hours after stroke with a mismatch between deficit and infarct. N Engl J Med. 2018;378(1):11-21.

45. Albers GW et al. Thrombectomy for stroke at 6 to 16 hours with selection by perfusion imaging. $\mathrm{N}$ Engl J Med. 2018:378(8):708-18.

46. Chandra RV et al. Does the use of IV tPA in the current era of rapid and predictable recanalization by mechanical embolectomy represent good value? J Neurointer Surg. 2016;8(5):443-6.

47. Gariel F et al. Mechanical thrombectomy outcomes with or without intravenous thrombolysis: insight from the ASTER randomized trial. Stroke. 2018:49(10):2383-90.

48. Mistry EA et al. Mechanical thrombectomy outcomes with and without intravenous thrombolysis in stroke patients: a meta-analysis. Stroke. 2017;48(9):2450-6.

49. Kaesmacher $\mathrm{J}$ et al. Direct mechanica thrombectomy in tPA-ineligible and-eligible patients versus the bridging approach: a meta-analysis. $J$ Neurointervent Surg. 2019;11(1):20-7.

50. Phan $\mathrm{K}$ et al. Endovascular therapy including thrombectomy for acute ischemic stroke: a systematic review and meta-analysis with trial sequential analysis. J Clin Neurosci. 2016;29:38-45.

51. Martin GP et al. Do frailty measures improve prediction of mortality and morbidity following transcatheter aortic valve implantation? An analysis of the UK TAVI registry. BMJ. 2018;8(6):e022543.

52. Duffy $\mathrm{S}$ et al. Per-pass analysis of thrombus composition in patients with acute ischemic stroke undergoing mechanical thrombectomy. Stroke. 2019;50(5):1156-63.

53. Adams $\mathrm{DH}$ et al. Transcatheter aortic-valve replacement with a selfexpanding prosthesis. N Engl J Med. 2014;370(19):1790-8. 
54. Reardon MJ et al. 2-year outcomes in patients undergoing surgical or self-expanding transcatheter aortic valve replacement. J Am Col Cardiol. 2015;66(2):113-21.

55. Reardon MJ et al. Surgical or transcatheter aortic-valve replacement in intermediaterisk patients. N Engl J Med. 2017;376(14):1321-31.

56. Wang $J$ et al. Risk factors for postTAVI bleeding according to the VARC-2 bleeding definition and effect of the bleeding on short-term mortality: a meta-analysis. Can J Cardiol. 2017;33(4):525-34.
57. Bagur R. Transcatheter aortic valve looking for low-risk patients: a post hoc analysis of SURTAVI keeps opening the door. Eurolntervention. 2018;14(8):846.

58. Siontis GC et al. Transcatheter aortic valve implantation vs. surgical aortic valve replacement for treatment of symptomatic severe aortic stenosis: an updated meta-analysis. Europe Heart J. 2019;40(38):3143-53.

59. Castaño $\mathrm{C}$ et al. Mechanical thrombectomy with 'ADAPT' technique by transcervical access in acute ischemic stroke. Neuro J. 2015;28(6):617-22.
60. White CJ. Acute stroke intervention: the role of interventional cardiologists. J Am Coll Cardiol. 2019;73(12):1491-3.

61. Holmes Jr DR, Hopkins LN. Interventional cardiology and acute stroke care going forward: JACC review topic of the week. J Am Coll Cardiol. 2019;73(12):1483-90.

62. Medtronic. 2017. Bridging thrombolysis versus direct mechanical thrombectomy in acute ischemic stroke. NCTO3192332. https:// clinicaltrials.gov/ct2/show/ NCT03192332. 